\title{
O USO DAS TECNOLOGIAS DIGITAIS NA EDUCAÇÃO DO SÉCULO XXI
}

\author{
USO DE LAS TECNOLOGÍAS DIGITALES EN LA EDUCACIÓN DEL SIGLO XXI
}

\author{
THE USE OF DIGITAL TECHNOLOGIES IN THE EDUCATION OF THE 21ST \\ CENTURY
}

\author{
Priscilla Aparecida Santana BITTENCOURT ${ }^{1}$ \\ João Pedro ALBINO ${ }^{2}$
}

\begin{abstract}
RESUMO: A presente investigação elaborou um breve panorama dos temas relacionados aos nativos digitais e a educação no século XXI. O uso das tecnologias na educação tem sido um desafio com algumas questões em aberto, tais como: por que e como utilizar mídias digitais na educação e quais mídias utilizar. A facilidade de acesso das tecnologias digitais pelos jovens obriga o processo de ensino-aprendizagem se adaptar, para preparar e desenvolver cidadãos críticos e ativos. Com o intuito de levantar dados e refletir sobre as tecnologias digitais e a sua utilização no processo educativo dos nativos digitais, foi realizada, inicialmente, uma pesquisa bibliográfica sobre a origem dos nativos digitais e a sua correlação com as tecnologias da informação e comunicação. Posteriormente serão elaboradas pesquisas quantitativa e qualitativa para serem aplicadas na comunidade acadêmica (alunos e professores) em duas escolas de nível médio, uma pública e outra privada. Os resultados serão analisados e comparados com o objetivo de validar a pergunta de pesquisa e contribuir para discutir os desafios e possibilidades do uso das tecnologias na educação. Até o momento pode inferir que é preciso aprofundar o estudo sobre o conceito de mídias digitais e seu uso no processo educativo
\end{abstract}

PALAVRAS-CHAVE: Nativos digitais. Tecnologias. Educação. Ensino-aprendizagem.

RESUMEN: La presente investigación desarrollado un breve panorama de los temas relacionados a los nativos digitales y la educación el siglo XXI. El uso de las tecnologías en la educación es un desafío con muchas cuestiones en abierto, tales como: por qué y como utilizar mass media digitales en la educación y cuáles mass media utilizar. La facilidad de acceso de las tecnologías digitales por los jóvenes obliga el proceso de enseñanzaaprendizaje adaptarse, para preparar y desarrollar ciudadanos críticos y activos. Con el objetivo de levantar datos y reflejar sobre las tecnologías digitales y su utilización en el proceso educativo de los nativos digitales, fue realizada, inicialmente, una investigación bibliográfica sobre el origen de los nativos digitales y su correlación con las tecnologías de la información y comunicación. Posteriormente serán elaboradas investigaciones cuantitativa y cualitativa para que sean aplicadas en la comunidad académica (alumnos y profesores) en dos escuelas de nivel medio, una pública y otra privada. Los resultados serán analizados y comparados con el objetivo de validar la pregunta de investigación y contribuir para discutir los desafíos y posibilidades del uso de las tecnologías en la educación. Hasta el

${ }^{1}$ Doutoranda pelo Programa de Pós-graduação em Mídia e Tecnologa, FAAC/Unesp, campus de Bauru. Bolsista capes. Email: priscillasant@gmail.com

${ }^{2}$ Professor Doutor na Universidade Estadual Paulista Júlio de Mesquita Filho (UNESP), Faculdade de Ciências de Bauru, Departamento de Computação. Email: jpalbino@fc.unesp.br 
momento puede inferir que es preciso profundizar el estudio sobre el concepto de mass media digitales y su uso en el proceso educativo.

PALAVRAS CLAVE: Nativos digitales. Tecnologías. Educación. Enseñanza-aprendizaje.

ABSTRACT: This research has provided a brief overview of the topics related to digital natives and education in the 21st century. The use of technologies in education has been a challenge with some open questions, such as: why and how to use digital media in education and what media to use. The ease of access of digital technologies by young people requires the teaching-learning process to adapt, to prepare and develop critical and active citizens. In order to collect data and reflect on digital technologies and their use in the educational process of digital natives, a bibliographical research was first carried out on the origin of digital natives and their correlation with information and communication technologies. Subsequently, quantitative and qualitative research will be developed to be applied in the academic community (students and teachers) in two middle schools, one public and one private. The results will be analyzed and compared with the objective of validating the research question and contribute to discuss the challenges and possibilities of the use of technologies in education. To date, it may be inferred that further study is needed on the concept of digital media and its use in the educational process.

KEYWORDS: Digital natives. Technologies. Education. Teaching-learning.

\section{Introdução}

Vive-se a emergência de uma sociedade conectada. O dia-a-dia da sociedade, organizações e governos, depende cada vez mais das tecnologias de informação e comunicação (TIC) e sobretudo da internet.

A velocidade da circulação das informações estão cada dia mais rápidas, gerando instabilidades constantes conforme afirma Martino (2014):

\footnotetext{
A circulação de informações encontra nas redes o melhor tipo de arquitetura. A velocidade da circulação de informações significa também que novidades estão presentes o tempo todo, gerando como padrão uma instabilidade constante, Qualquer informação pode ser alterada, completada ou cancelada por uma nova, muitas vezes se deixar indícios dos caminhos seguidos. (MARTINO, 2014)
}

Um dos desafios que a sociedade e as instituições de ensino encontram neste momento é a falta de conhecimento e treinamento em mídias digitais de toda comunidade acadêmica. Esse pode ser um dos fatores que têm contribuído para a não utilização adequada das novas tecnologias disponíveis nas atividades de ensino e aprendizagem. 
Segundo Castells (2006, p.17):

O nosso mundo está em processo de transformação estrutural desde a década de 1980 do Século XX. Tal transformação é um processo multidimensional, mas está associado à emergência de um novo paradigma tecnológico, baseado nas tecnologias de comunicação e informação, que teve início nos anos 1960 e que se difundiram de forma desigual por todo o mundo.

O avanço das tecnologias de informação e comunicação pode ser o motivo que favoreceu para que as instituições de ensino e, em particular as formas de ensinoaprendizagem, não acompanhassem a evolução e disponibilidade tecnológica.

Considerando-se a necessidade da comunidade acadêmica de se equiparar à tecnologia, a importância da disseminação do conhecimento e a inovação tecnológica em constante mudança, adotou-se como questão de pesquisa a seguinte pergunta: Como o uso das mídias digitais (computadores, tablets, internet, etc) pode colaborar para melhorar o ensinoaprendizagem nas instituições de ensino?

Perrenoud (1999) destaca que, a melhoria do processo de aprendizagem e familiarização dos alunos com as novas tecnologias exigem a necessidade de se desenvolver competências.

Estabelecendo que uma destas competências é o uso da tecnologia na educação, Perrenoud (1999) sugere que em situações-problema, os professores utilizem de preferência softwares didáticos ou aplicativos que auxiliem diariamente as mais diversas tarefas intelectuais.

Conforme Bariani (2011) existe uma grande discrepância entre o papel interativo do indivíduo desempenhado fora das salas de aula em meio aos ambientes virtuais (os adolescentes "nativos digitais") e entre o posicionamento usualmente passivo ao qual o estudante é condicionado (na sala de aula).

Este trabalho se propõe a se concentrar nos benefícios que algumas destas novas mídias, em especial a hipermídia, pode trazer às instituições de ensino ao criar um vínculo entre o meio acadêmico e o ambiente cotidiano multimídia em que o aluno já se encontra inserido.

A Educomunicação, a qual segundo Soares (2006), propõe novos tipos de aprendizagem, utilizando recursos tecnológicos e novas relações na comunicação, e a hipermídia (a reunião de várias mídias num suporte computacional, suportado por sistemas eletrônicos de comunicação), de acordo com Parente (1999) questionam o sistema metodológico que privilegiou os caminhos lógicos e científicos atuais que ficaram alheios às transformações dos novos meios comunicacionais. 
No contexto apresentado neste trabalho, a TIC substitui o quadro negro, enquanto ferramenta. Já a Educomunicação coloca a sua ênfase no processo, ou seja, apesar de o conteúdo e o efeito fazerem parte de toda ação pedagógica, o processo educomunicativo não estabelece um "teto de desenvolvimento do conhecimento", o qual permite uma série de abordagens.

Neste estudo foi realizada uma pesquisa bibliográfica para refletir sobre a educação no século XXI e o perfil dos nativos digitais.

Em seguida serão elaboradas pesquisas quantitativa e qualitativa para serem aplicadas na comunidade acadêmica (alunos e professores) em duas escolas de nível médio com curso técnico de informática, uma pública e outra privada.

Os resultados serão analisados e comparados com o objetivo de validar a pergunta de pesquisa.

\section{A Educação no século XXI}

Conforme afirma Prensky (2010, p.1) “Our students have changed radically. Today's students are no longer the people our educational system was designed to teach". ${ }^{3}$

Estamos vivenciando uma nova realidade, a era da informação e da tecnologia, a qual os alunos, professores e a sociedade geral, mudaram seus pensamentos e a sua forma de agir. Assim como tudo mudou ao longo dos anos, a educação também mudou nos últimos anos.

Delors (2001, p. 54) acredita que, "A educação pode ser um fator de coesão, se procurar ter em conta a diversidade dos indivíduos e dos grupos humanos, evitando tornar-se um fator de exclusão social, pois o respeito pela diversidade e pela especificidade dos indivíduos constitui, de fato, um princípio fundamental".

Uma pesquisa realizada pelo cetic.br (2013) com o objetivo de investigar as oportunidades e riscos associados ao uso da internet por crianças e adolescentes brasileiros, com idade entre 9 a 17 anos, e com 2.261 entrevistados, mostra que em 2013, o local de acesso à internet foi de 37\% nas escolas.

Castells (2005, p. 11) relata sobre a os usos de softwares "open source" afirmando que,

${ }^{3}$ Tradução da autora: "Nossos estudantes mudaram radicalmente. Os estudantes da atualidade não são mais as pessoas a quem o sistema educacional foi projetado" 
Se não houver um acesso universal da população ao amplo mundo dos computadores em rede com tecnologias não teremos domínio e conteúdos, não teremos garantias nem da democratização digital nem da generalização da economia e dos benefícios sociais pelos avanços tecnológicos.

De acordo com Lutz (2014), as novas tecnologias, em especial na área da informática, estão cada vez mais presentes no cotidiano dos alunos, sendo que aqueles que não se adaptarem a essa realidade, correm o risco de serem considerados analfabetos tecnológicos. Portanto, para evitar tal situação, as escolas, com a responsabilidade de preparar e desenvolver o aluno para atuar como cidadão crítico e ativo na sociedade, começam a observar a necessidade de seguir o ritmo do desenvolvimento tecnológico.

Conforme Martino (2014) a tecnologia "mais do que um suporte para mensagens, é um elemento decisivo na formação da mente, dos modos de sentir, perceber e compreender a realidade".

\section{Tecnologias digitais na educação}

A utilização cada vez maior, das mídias digitais no ambiente acadêmico e corporativo como estratégia, com um público cada vez mais envolvido com a tecnologia, trazem para as instituições várias opções de recursos didáticos para lhes dar a oportunidade de responder às diferenças individuais e às múltiplas facetas da aprendizagem.

Há algum tempo as mídias digitais estão disponíveis para a utilização em vários locais, como: empresas, supermercados, em casa, em terminais de agência bancária, para compra de ingressos de shows, teatros e cinema e tantos outros.

Provavelmente um dos locais em que menos se utiliza as mídias digitais seriam as escolas, principalmente pelos docentes no ensino-aprendizagem e no processo educacional.

Entretanto, de acordo com Daniel (2003, p. 54), “em todas as partes do mundo a tecnologia em evolução é a principal força que está transformando a sociedade".

Acredita-se que o uso das mídias digitais tem sido um grande desafio para muitos no ensino-aprendizagem, talvez porque ainda haja algumas questões e indagações que não foram respondidas como: Por que se deve usar as mídias digitais na educação? Como usá-la? Quais mídias utilizar? (DANIEL, 2003, p. 54).

Entretanto, a tecnologia não é dotada de perfeições quanto à suas vantagens e objetivos, e muitos autores começam a questionar se realmente a facilidade encontrada nos 
avanços tecnológicos na educação provocam grandes desvantagens, pontos negativos e manipulação nos relacionamentos interpessoais, comunicação e práticas de ensino dentro e fora da escola.

Por isso, Saviani (2007, p. 48) afirma que "considerando-se que a educação visa à promoção do homem, são as necessidades humanas que irão determinar os objetivos educacionais".

Sabe-se que a educação é a base fundamental do processo de desenvolvimento do ser humano, e isto já vem sendo discutindo ao longo dos anos, seja por educadores, acadêmicos, entre outros.

Neste contexto a educação enfrenta desafios, seja de reflexão no ensino-aprendizagem e na capacitação dos educadores, que são as pessoas que se esforçam para se adaptar ao uso das novas tecnologias, definidos como imigrantes digitais em Prensky (2001), e estão acostumados com outra didática e outras formas de ensino-aprendizagem.

Segundo Castells (1999, p. 21) "uma revolução tecnológica concentrada nas tecnologias da informação está remodelando a base material da sociedade em ritmo acelerado".

Para Freitas e Almeida (2012, p. 32):

Dentro de uma nova pedagogia que acolha metodologias de ensino com o uso das TIC's, além da facilidade e da qualidade de informações que se tornam disponíveis e das inúmeras possibilidades de um processo de aprendizagem interativo/construtivo, espera-se contribuir para a autonomia intelectual do aluno. Ao adaptar-se ao uso das tecnologias, ela poderá buscar respostas às suas próprias inquietações, e essa busca - incluindo-se aí a seleção e análise das informações, é uma das maiores contribuições que a aprendizagem pela tecnologia pode dar ao aluno.

Freitas e Almeida (2012, p. 32) também afirmam que,

Uma nova prática pedagógica deverá mostrar que a utilização das TIC's na escola precisa ser feita de maneira interativa e não apenas expositiva, ou seja, o aluno deve atuar sobre as tecnologias, interagindo, pesquisando, interpretando, refletindo, construindo e agregando conhecimentos. Ela inicia, mas vai muito além do uso das mídias para a simples exposição de conteúdo, como substitutos de cartazes ou da própria lousa.

E também afirma Castells (2005, p. 19),

É por isso que difundir a Internet ou colocar mais computadores nas escolas, por si só, não constituem necessariamente grandes mudanças sociais. Isso depende de onde, por quem e para quê são usadas as tecnologias de comunicação e informação. O que nós sabemos é que esse paradigma tecnológico tem capacidades de performance superiores em relação aos anteriores sistemas tecnológicos. Mas para saber utilizá-lo no melhor do seu potencial, e de acordo com os projectos e as decisões de cada sociedade, 
precisamos de conhecer a dinâmica, os constrangimentos e as possibilidades desta nova estrutura social que lhe está associada: a sociedade em rede.

\section{Mídias digitais}

E o que são mídias digitais?

Martino (2014, p. 10), afirma que, "há uma quantidade considerável de respostas disponíveis, nem sempre dialogando entre si”.

Na Tabela 1, pode-se visualizar alguns eixos temáticos das mídias digitais na comunicação.

Tabela 1 - Eixos temáticos das mídias digitais na comunicação.

\begin{tabular}{|l|l|l|l|}
\hline \multicolumn{1}{|c|}{$\begin{array}{c}\text { Visão de mídia e/ou } \\
\text { internet }\end{array}$} & \multicolumn{1}{|c|}{ Contexto } & \multicolumn{1}{c|}{$\begin{array}{c}\text { Tecnologias } \\
\text { principais }\end{array}$} & \multicolumn{1}{c|}{ Alguns Autores } \\
\hline $\begin{array}{l}\text { Mediador das relações } \\
\text { pessoais }\end{array}$ & $\begin{array}{l}\text { Estados Unidos; } \\
\text { Europa, América } \\
\text { Latina, 1990s. }\end{array}$ & $\begin{array}{l}\text { Computador, } \\
\text { Smartphones; Tablets; } \\
\text { Inteligência Artificial }\end{array}$ & $\begin{array}{l}\text { Turkle; Baym; } \\
\text { Papacharisi; Wellman }\end{array}$ \\
\hline Redes Sociais & $\begin{array}{l}\text { Estados Unidos, 1960; } \\
\text { Estados Unidos, } \\
\text { Europa, América } \\
\text { Latina, 2000 }\end{array}$ & $\begin{array}{l}\text { Redes de } \\
\text { computadores; } \\
\text { Smartphones; Tablets }\end{array}$ & $\begin{array}{l}\text { Barnes; Baran; } \\
\text { Granovetter; Benkler; } \\
\text { Castells }\end{array}$ \\
\hline $\begin{array}{l}\text { Espaço de tensão politica, } \\
\text { hegemonia e resistencia }\end{array}$ & $\begin{array}{l}\text { Europa, 1990; América } \\
\text { Latina, 2000. }\end{array}$ & $\begin{array}{l}\text { Redes de } \\
\text { computadores; } \\
\text { Smartphones; Tablets }\end{array}$ & $\begin{array}{l}\text { Castells; Naxar; } \\
\text { Dalhgren; Wolton; Keen; } \\
\text { Canclini; Sarle }\end{array}$ \\
\hline
\end{tabular}

Fonte: MARTINO (2014, p. 16). Adaptado pela autora, 2015.

De acordo com Martino (2014, p. 17), a tabela 1, “dá uma ideia de pluralidade de temas, perspectivas e abordagens possíveis para se pensar as mídias digitais. Cada autor, em geral, se dedica a estudar um aspecto do problema, e constrói suas teorias e conceitos".

Neste trabalho utilizou-se para mídias digitais como principais tecnologias, os computadores, tablets, smartphones e internet.

\section{Os nativos digitais}

No cenário atual que vivemos, há espaço para as tecnologias digitais que existem e as que ainda estão em desenvolvimento. 
Nos deparamos a todo momento com as tecnologias em toda a parte. Adolescentes com dispositivos móveis, smartphohes e tablets, digitando velozmente textos de mensagens. Um garoto de apenas 7 anos consegue facilmente acessar jogos, ensinar outras pessoas a utilizarem tal ambiente virtual, e também manipular tais dispositivos de forma mais rápida do que podemos inferir.

Segundo Palfrey e Gasser (2011, p. 11) assinala que, "Todos [estes garotos e garotas] são nativos digitais. Todos nasceram depois de 1980, quando as tecnologias digitais, chegaram. Todos [eles] têm acesso as tecnologias digitais e todos têm habilidades para usar essas tecnologias".

Já para Prensky (2001) o termo nativo digital foi sugerido para designar os nascidos a partir de 1990 e que apresentam características como familiaridade com o computador, com os recursos da internet e a capacidade de receber em informações rapidamente, processar em vários assuntos simultaneamente e desempenhar em múltiplas tarefas.

Como nem todos têm fácil acesso ao computador e aos recursos da internet, pode-se falar em usuários nativos digitais sem associá-los diretamente a uma faixa etária específica.

Lemos $(2009$, p. 40) afirma também que, “os sujeitos que nasceram imersos no mundo digital interagem simultaneamente com as diferentes mídias, isto é, ouvem música, jogam videogames, veem DVD, conversam com os amigos nos softwares de comunicação instantânea ou em telefones, fazem as atividades escolares, tudo isso ao mesmo tempo".

\section{Considerações Finais}

Com este estudo acerca da utilização da tecnologia na educação é possível chegar a algumas considerações.

De acordo com Lutz (2014), as novas tecnologias, em especial na área da informática, estão cada vez mais presentes no cotidiano dos alunos, sendo que aqueles que não se adaptarem a essa realidade, correm o risco de serem considerados analfabetos tecnológicos. Para evitar tal situação, as escolas, com a responsabilidade de preparar e desenvolver este aluno para atuar como cidadão crítico e ativo na sociedade, começam a observar a necessidade de seguir o ritmo do desenvolvimento tecnológico.

Durante a construção desta proposta de pesquisa, foi possível estudar conceitos das mídias digitais (computadores, tablets, internet, etc), e refletir em como elas podem colaborar 
para melhorar o ensino-aprendizagem nas instituições de ensino apoiando o processo didático e pedagógico.

O resultado desta revisão bibliográfica indicou, até o momento, que é preciso estudar o conceito de mídias digitais e fluxo de informações na educação, afim de nortear profissionais e estudantes desta área.

Se faz necessário um olhar acadêmico para que assim se consiga oferecer novas formas de motivação para o aprendizado e novas maneiras de inclusão social, por meio do uso criativo das mídias e tecnologias disponíveis.

E a partir dos conceitos apresentados neste estudo, percebe-se que apesar dos desafios que existe na educação brasileira, existem também grandes possibilidades para alavancar a educação no século XXI a partir do uso criativo das tecnologias digitais disponíveis, como apoio no ensino-aprendizagem.

AGRADECIMENTOS: Coordenação de Aperfeiçoamento de Pessoal de Nível Superior

\section{Referências}

BARIANI, B. B.; Hipermídia e Educomunicação: o papel das novas mídias digitais no ensino, Revista Sessões do Imaginário, Ano XVI, no. 25, janeiro de 2011.

CASTElls, M.; CARDOSO, G. DEBATE: A Sociedade em rede - Do conhecimento à ação política. 2005, Centro Cultura de Belém. Disponível em: <http://www.egov.ufsc.br/portal/sites/default/files/anexos/a_sociedade_em_rede__do_conhecimento_a_acao_politica.pdf>. Acesso em: 15 jul. 2016

Comitê Gestor da Internet no Brasil. Pesquisa sobre o uso das tecnologias de informação e comunicação nas escolas Brasileiras. TIC educação. Disponível em: < http://cetic.br/media/docs/publicacoes/2/tic-educacao-2013.pdf>. Acesso em: 10 nov. 2015.

DANIEL, J. Educação e tecnologia num mundo globalizado. Brasília: UNESCO, 2003.

DELORS, J.; Educação: Um tesouro a descobrir. 6 ed., São Paulo: Cortez: Brasília, DF: MEC: UNESCO, 2001.

FREITAS, M. C. D., ALMEIDA, M. G. Docentes e discentes na sociedade da informação (A escola no Século XXI; v.2). Rio de Janeiro: Brasport, 2012. 
LEMOS, S. Nativos digitais $\mathbf{x}$ aprendizagens: um desafio para a Escola, Boletim Técnico do Senac: a R. Educ. Prof., Rio de Janeiro, v. 35, n.3., set/dez, 2009. Disponível em: <http://www.senac.br/BTS/353/artigo-04.pdf>. Acesso em: 06 de jun. 2016.

LUTZ, M. R.; Utilização de mídias digitais como metodologia de ensino-aprendizagem de matemática, PROJETO DE CURTA DURAÇÃO, Instituto Federal de Farroupilha, Campus Alegrete, 2014.

MARTINO, Luís Mauro Sá. Teoria das Mídias Digitais: Linguagens, ambientes, redes. Petrópolis, RJ: Vozes, 2014.

PARENTE, A.; O Virtual e o Hipertextual. Rio de Janeiro: Pazulin, 1999.

PALFREY, J. GASSER, U. Nascidos na era digital: entendendo a primeira geração de nativos digitais. tradução: Magda França Lopes; revisão técnica: Paulo Gileno Cysneiros. Porto Alegre: Artmed, 2011

PERRENOUD, P. Construir as competências desde a escola. Porto Alegre: Artmed, 1999.

PRENSKY, M. Digital Natives, Digital Immigrants. MCB University Press, 2001. Disponível em: $\quad$ http://www.marcprensky.com/writing/Prensky\%20\%20Digital\%20Natives, \%20Digital\%20Immigrants\%20-\%20Part1.pdf >. Acesso em: 25 fev 2015.

SAVIANI, D. História das ideias pedagógicas no Brasil. Campinas, SP: Autores Associados, 2007.

SOARES, D. Educomunicação: o que é isto? Disponível em: 〈http://www.portalgens.com.br/baixararquivos/textos/educomunicacao_o_que_e isto.pdf $>$. 2006. Acesso em: 15 out. 2015.

\section{Como citar este artigo:}

BITTENCOURT, Priscilla Aparecida Santana.; ALBINO, João Pedro. O uso das tecnologias digitais na educação do século XXI. Revista Ibero-Americana de Estudos em Educação, Araraquara, v.12, n.1, p. 205-214, 2017. Disponível em: <http://dx.doi.org/10.21723/riaee.v12.n1.9433>. E-ISSN: 1982-5587.

Data de submissão: jul/2016

Aprovação final: fev/17 